\title{
Verdad científica y universidad pública
}

"La hora de la verdad es su colisión con la realidad. La verdad científica se inclina ante la realidad, no importa la autoridad ni el prestigio de quien haya enunciado la verdad antigua o la nueva". (Wagensberg, 2002).

$\mathrm{L}$ a universidad pública, una de las más admirables conquistas de las clases trabajadoras en la historia de la humanidad, sufre el embate de un ciclo de neoliberalismo avanzado en varios países de la región, agravado por la fuerza de la pandemia del Covid-19, lo que acentúa las profundas desigualdades sociales existentes. Sin embargo, esta editorial no pretende dar indicaciones para el porvenir de la divulgación científica 'tras la catástrofe' dado que apenas nos encontramos atravesando unos meses de su estallido mundial. Por ahora solo nos preguntamos sobre las consecuencias que acarrean las ciencias y su divulgación en medio de este lodazal y cómo encarar esta anomalía global en el horizonte de una búsqueda de la verdad promovida por la investigación científica.

No podemos negar, en esta etapa de nuestra existencia editorial, la importancia de la presencialidad para descubrir y experimentar todo aquello que hace a la vida digna de ser vivida. El peso de la Universidad en este caso es invaluable, digamos, por lo que pasa en ella, especialmente en lo referente a lo que planteaba Humboldt cuando decía que el profesor ya no se debe al alumno, sino que ambos, profesor y alumno, se deben a la verdad. Así, el catedrático Fernández Liria (2020) nos propone llamar presencialidad a eso capaz de hacer presente "todo aquello por lo que merece la pena estar vivo, la verdad, la justicia y la belleza".

En primer lugar, vamos a coincidir con el profesor Fernández Liria en la idea de que proclamar ahora una gran ocasión para afrontar los nuevos retos y desafíos de la universidad pública, no resolverá en nada la humillación que nos está propinando el manejo neoliberal de la crisis, desplegándose las condiciones idóneas para la reducción de la investigación pública por el mecenazgo privado en un nuevo escenario de virtualidad forzada y la irrupción de tecnologías de la comunicación, que buscan revolucionar la velocidad y e modus operandi de los procesos educativos, con el apagón definitivo de aquella presencialidad. Si todo esto provoca vértigo, ¿qué decir de la disminución sistemática de los presupuestos públicos enfáticamente en los rubros que suponen el avance de las ciencias? Entonces, ¿por qué confiar decididamente en la investigación científica, y qué rol cumple Estoa en este pilar de la educación pública?

Podemos partir de una premisa de Jorge Wagensberg bajo la cual existe una ética basada en la búsqueda de la verdad científica, una verdad que elude a la realidad más que al conocimiento y que guarda un interés legítimo en e experimento dentro de la fase de la investigación. Allí, plantea Wagensberg, "experimentar es conversar con la realidad" (2002). En esta dirección, el conocimiento específico, como el que persigue cada edición de la revista Estoa, nace de una verdad (en la ciencia) fundada en la fidelidad a los tres principios (método) señalados por el científico español: objetividad, inteligibilidad, y el principio dialéctico.

De acuerdo al principio de objetividad, la verdad científica tiende a ser universal. El principio de inteligibilidad promete que la realidad más inteligible es la más compacta e irreductible: la palabra, la fórmula, etc. Aquí la verdad científica sirve para comprender un trozo de la realidad, tendiendo a ser útil para anticiparse a la incertidumbre. Por último, de todas las maneras de representar la realidad, e principio dialéctico es el que más se arriesga a entrar en contradicción con la realidad misma, ayudando a la ciencia a ser coherente y completa. La verdad científica, en virtud de este principio, necesariamente cambia, siendo una verdad con minúscula, provisional, inacabada, pudiendo actualizarse una verdad por otra. Esta es la grandeza de la verdad científica y la razón fundamental de la existencia de Estoa desempeñándose en la universidad pública, en donde, además, la ciencia es y deberá ser una ciencia abierta. En esta perspectiva, es digno señalar que la Universidad de Cuenca y su Facultad de Arquitectura y Urbanismo no claudican a la urgencia de defender y respaldar los procesos que propician la búsqueda de esa verdad científica y multiforme revelada en revistas como Estoa.

En momentos de crisis concurrentes atravesadas por tragedias personales, locales y globales, el proceso editorial no se detuvo, y si en algo hemos de pararnos es únicamente para manifestar un reconocimiento al esfuerzo añadido de autores y autoras, a la generosidad académica de evaluadores y evaluadoras, todos ellos decididos a continuar, a pesar de la fractura repentina de lo cotidiano, porque comprenden la delicada importancia de investigar en este mundo. Por supuesto, de igual forma mi agradecimiento a Equipo editorial de la revista Estoa y al Comité científico que lo acompaña. En esta segunda edición del 2020 se publican doce artículos pertenecientes a 15 autoras y 11 autores con filiación a 15 universidades en 7 países (España, Argentina, Brasil, Cuba, Chile, Ecuador, y Colombia), contando con la participación de más de 30 evaluadores académicos internacionales.

Consideramos que este abnegado número no solo llega puntual, sino que perdurará discretamente en la historia de la revista por poblar el confinamiento social de diversas aproximaciones a la realidad, desde la arquitectura hasta el urbanismo, y por permitir la conversación masiva entre las investigaciones, dejando que la sociedad y la academia se nutran de ellas. Como diría Fernández Liria, "nosotros no necesitamos triunfar en los negocios, sino trabajar en la verdad, reflexionar sobre la justicia y agradecer que en este mundo haya poesía y belleza" (2020).

\section{Referencias bibliográficas}

Fernández Liria, C. (2020). La Universidad vaciada. Cuarto Poder. Recuperado de https://www.cuartopoder.es/ ideas/2020/05/15/la-universidad-vaciada-carlos-fernandezliria/

Wagensberg, J. (2002). La verdad en ciencia. Letras Libres. Recuperado de https://www.letraslibres.com/mexicoespana/la-verdad-en-ciencia

Pedro Jiménez-Pacheco pedro.jimenezp@ucuenca.edu.ec 